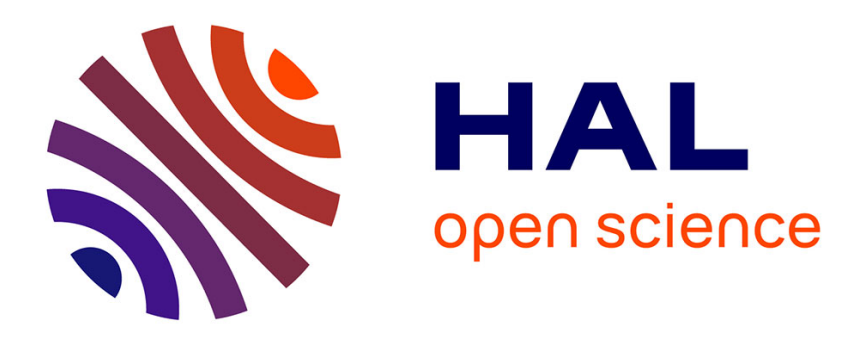

\title{
Optimal control for Diesel engine combustion regime
}

Mihaela-Ancuta Mone, Sette Diop, Dumitru Popescu

\section{To cite this version:}

Mihaela-Ancuta Mone, Sette Diop, Dumitru Popescu. Optimal control for Diesel engine combustion regime. 2019 22nd International Conference on Control Systems and Computer Science (CSCS), May 2019, Bucharest, Romania. pp.42-47, 10.1109/CSCS.2019.00015 . hal-02414179

\section{HAL Id: hal-02414179 \\ https://hal.science/hal-02414179}

Submitted on 23 Dec 2020

HAL is a multi-disciplinary open access archive for the deposit and dissemination of scientific research documents, whether they are published or not. The documents may come from teaching and research institutions in France or abroad, or from public or private research centers.
L'archive ouverte pluridisciplinaire HAL, est destinée au dépôt et à la diffusion de documents scientifiques de niveau recherche, publiés ou non, émanant des établissements d'enseignement et de recherche français ou étrangers, des laboratoires publics ou privés. 


\section{Optimal control for Diesel engine combustion regime}

\author{
$1^{\text {st }}$ Mihaela-Ancuta Mone \\ Faculty of Automatic Control and Computers \\ University Politehnica of Bucharest \\ Bucharest, Romania \\ mihaela.mone@stud.acs.upb.ro
}

\author{
$2^{\text {nd }}$ Sette Diop \\ Laboratoire des Signaux \& Systemes \\ CentraleSupelec \\ Gif sur Yvette, France \\ sette.diop@12s.centralesupelec.fr
}

\author{
$3^{\text {rd }}$ Dumitru Popescu \\ Faculty of Automatic Control \\ University Politehnica of Bucharest \\ Bucharest, Romania \\ dumitru.popescu@acse.pub.ro
}

\begin{abstract}
This paper presents dynamic models associated to an experimental Diesel engine platform. Stability, controllability and observability analysis of the models have been performed. While the impact on human's health of NOx emissions is addressed, a state-feedback control procedure is presented in order to control the air flow inside the intake manifold to the cylinders and the pressure inside the combustion chamber of the experimental Diesel engine. The proposed solution of optimal control of the combustion regime brings important improvements of the Diesel engine: NOx reduction and fuel saving.
\end{abstract}

Index Terms-Diesel engine, models, state-feedback control, optimal control, genetic algorithms

\section{INTRODUCTION}

The Diesel engine has transformed the modern world. It is a versatile engine, having been used in many applications such as ships and trains, submarines and vans, tractors and motorcycles. The vast majority of the world's commercial, industrial, agricultural, mining and military vehicles are powered by Diesel. A 19th century invention became the 21st century's most important engine. There have been performed many analyses with respect to the pros and cons of Diesel engines utilization with respect to human health. On one hand, it is desired the NOx reduction with a direct impact on humans health and environment pollution, and, on the other hand, reduction of consumed fuel. As a NOx reduction technology, we can point out the interest in urea-based selective catalytic reduction (SCR) [1], [2], [3], [4], [5].

Blended bio fuel is a effective alternative fuel for fossil fuels in requisites of pollution reduction in emission and efficiency increased in engine; particulate matter (PM) and NOx emitted from Diesel engines is simultaneously reduced by a barriertype catalyst packed nonthermal plasma (NTP) application [6].

Experimental results prove that it is possible to reduce pollutant emissions in addition to fuel consumption, even with a small hybridization level. In this case, transient torque optimization is the key factor [7].

Technique of ozone injection to induce reactions leading to NO conversion in a diesel engine exhaust and subsequent adsorption by lignite ash, an industrial waste from lignite coal red power plants [8]. Exhaust gas recirculation (EGR) is an important feature targeted on NOx emission reduction on marine Diesel engines. Recycled exhaust gas, at part load, can be used to reduce diesel engine NOx emissions [9].
Section II presents the dynamic models associated to the combustion regime of the experimental Diesel engine. The data used related to the engine models was obtained from the experimental platform present at the University Picardie Amiens, France [13], [14].

Section III presents the theoretical aspects related to the stability, controllability and observability of the associated engine models, for which control laws are discussed in sections IV and V [15], [16], [17].

The performance in simulation of the control laws and a comparative analysis of the results can be observed in section VI.

\section{ENGINE MODELS}

\section{A. State-space model with linear parameter-varying}

We consider the next state-space model with linear parameter-varying [18]:

$$
\left\{\begin{array}{l}
\dot{x}(t)=\mathbf{A}(\rho(t)) x(t)+\mathbf{B}(\rho(t)) u(t) \\
y(t)=\mathbf{C}(\rho(t)) x(t)+\mathbf{D}(\rho(t)) u(t)
\end{array}\right.
$$

where the matrices $\mathbf{A}, \mathbf{B}, \mathbf{C}$ and $\mathbf{D}$ depend on an unknown exogenous time-varying parameter, $\rho(t)$. In this paper, we consider this parameter as an internal one, thus it represents a state of the mathematical model.

Given the fact that $\mathbf{A}, \mathbf{B}, \mathbf{C}$ and $\mathbf{D}$ have a non-linear form, we want to obtain an approximate model of reduced order, but whose simplification to be compensated by the control laws further developed.

In order to obtain the mathematical model of the engine, we start from the ideal gas law:

$$
p V=\nu R T
$$

where $\nu$ is the quantity of ideal gas inside a sealed tube of volume $V$, having the pressure $p$ and the absolute temperature $T$ (i.e. Kelvin temperature scale). $R$ is the ideal gas constant having a value of $R=8.314 \frac{\mathrm{J}}{\mathrm{molK}}$.

By deriving the equation (2) with respect to time and writing one differential equation for intake and one for exhaust, we obtain the following equations which describe the dynamic of the system:

$$
\dot{p}_{i}=\frac{R T_{i}}{V_{i}}\left(W_{c i}+F_{i e}\right)+\frac{\dot{T}_{i}}{T_{i}} p_{i}
$$




$$
\begin{gathered}
\dot{p_{x}}=\frac{R T_{x}}{V_{x}}\left(F_{i c}+F_{f}-F_{x i}-F_{x t}\right)+\frac{\dot{T}_{x}}{T_{x}} p_{x} \\
\dot{P}_{c}=\frac{1}{\tau}\left(-P_{c}+P_{t}\right)
\end{gathered}
$$

where $p_{i}$ represents the intake manifold pressure, $p_{x}$ represents the exhaust manifold pressure. (5) represents the turbocharger's dynamic consisting in the power transfer with a delay of $\tau$.

The first approximation of the non-linear model given by (3) - (5) consists in considering the temperatures in the intake manifold and exhaust manifold at a constant value so that the effect of the variables $\dot{T}_{i}, \dot{T}_{x}, p_{i}$ and $p_{x}$ is not important.

The flow inside the EGR (i.e. $F_{x i}$ ) and the flow inside the VGT turbocharger (i.e. $F_{x t}$ ) are designed using the equation of flow through a pipe [19]. The variation of the air flow inside the intake manifold to the cylinders (i.e. $F_{i e}$ ) is determined using the speed - density equation.

In [11] are presented the intake and exhaust differential equations for a three-order state-space model, where $a, b, c$ and $d$ are identified parameters of the flow inside the VGT turbocharger (i.e. $F_{x t}$ ).

Considering these parameters at a constant value, also the temperatures inside the intake and exhaust manifolds, $T_{i}$ and $T_{x}$, respectively, we can say that (3) - (5) have constant parameters. This new model approximation does not affect the engine's dynamics at low variations, at least not in the domain of low and medium engine speed. But in reality, these parameters vary based on the operating point.

\section{B. Invariant model}

Based on (3) - (5), we obtain the following state-space model:

$$
\left\{\begin{array}{c}
\left(\begin{array}{c}
\dot{p}_{i} \\
\dot{p_{x}} \\
\dot{P}_{c}
\end{array}\right)=\mathbf{A}\left(\begin{array}{c}
p_{i} \\
p_{c} \\
P_{c}
\end{array}\right)+\mathbf{B}\left(\begin{array}{c}
A_{r} \\
x_{v} \\
N \\
W_{f}
\end{array}\right) \\
\left(\begin{array}{c}
W_{c i} \\
p_{i}
\end{array}\right)=\mathbf{C}\left(\begin{array}{c}
p_{i} \\
p_{x} \\
P_{c}
\end{array}\right)+\mathbf{D}\left(\begin{array}{c}
A_{r} \\
x_{v} \\
N \\
W_{f}
\end{array}\right)
\end{array}\right.
$$

where the inputs are given by $A_{r}$ (i.e. the position of the VGT valve), $x_{v}$ (i.e. the position of the EGR valve), $N$ (i.e. the engine speed) and $W_{f}$ (i.e. the fuel flow), the outputs are given by $W_{c i}$ (i.e. the mass air flow) and $p_{i}$ (i.e. the manifold absolute pressure) and the states are $p_{i}, p_{x}$ and $P_{C}$. The matrices $\mathbf{A}, \mathbf{B}, \mathbf{C}$ and $\mathbf{D}$ have appropriate dimensions, and the elements of $\mathbf{D}$ are considered zero. Therefore, we consider a three-order model.

\section{Reduced invariant model}

To reduce the model given by (6), the following approximation was made, by redefining the inputs given by EGR and VGT:

$$
\left\{\begin{array}{c}
A_{r}=\overline{A_{r}}+8.9 * 10^{-5}\left[\mathrm{~m}^{2}\right] \\
x_{v}=x_{v}+0.5
\end{array}\right.
$$

The dynamic of the engine is evaluated at a constant fuel flow $W_{f}$ and a constant engine speed $N$.

A new state-space representation is obtained, the number of inputs being reduced from four to two:

$$
\left\{\begin{array}{l}
\left(\begin{array}{c}
\dot{p}_{i} \\
\dot{p}_{x} \\
\dot{P}_{c}
\end{array}\right)=\mathbf{A}\left(\begin{array}{c}
p_{i} \\
p_{c} \\
P_{c}
\end{array}\right)+\mathbf{B}\left(\begin{array}{c}
A_{r} \\
x_{v}
\end{array}\right) \\
\left(\begin{array}{c}
W_{c i} \\
p_{i}
\end{array}\right)=\mathbf{C}\left(\begin{array}{c}
p_{i} \\
p_{x} \\
P_{c}
\end{array}\right)
\end{array}\right.
$$

where $\mathbf{A}, \mathbf{B}$ and $\mathbf{C}$ have the following form, each element being identified from (3) - (5):

$$
\left\{\begin{aligned}
\mathbf{A} & =\left[\begin{array}{lll}
a_{11} & a_{12} & a_{13} \\
a_{21} & a_{22} & a_{23} \\
a_{31} & a_{32} & a_{33}
\end{array}\right] \\
\mathbf{B} & =\left[\begin{array}{ll}
b_{11} & b_{12} \\
b_{21} & b_{22} \\
b_{31} & b_{32}
\end{array}\right] \\
\mathbf{C} & =\left[\begin{array}{lll}
0 & 0 & c_{13} \\
1 & 0 & 0
\end{array}\right]
\end{aligned}\right.
$$

\section{Stability, CONTROLLABILITY AND OBSERVABILITY} ANALYSIS

\section{A. Stability}

The first thing we want to do is analyze whether the openloop system is stable.

The system is stable if the system matrix, A, from (8) has all eigenvalues in the left half plane.

\section{B. Controllability}

For a system whose state-space representation is given by (1), in [10] there is defined the controllability matrix as:

$$
\mathrm{C}_{\mathrm{o}}=\left[\begin{array}{llll}
\mathrm{B} & \mathrm{AB} & \ldots & \mathbf{A}^{\mathrm{n}-1} \mathbf{B}
\end{array}\right]
$$

If the rank of the controllability matrix $\mathbf{C}_{\mathbf{o}}$ is the same as the one of the $\mathbf{A}$ matrix, then the system is controllable, i.e. there is a command acting on the output of the system.

\section{Observability}

The observability matrix is defined as follows:

$$
\mathbf{O}=\left[\begin{array}{llll}
\mathbf{C} & \mathbf{C A} & \ldots & \mathbf{C A}^{n-1}
\end{array}\right]^{T}
$$

If the rank of the observability matrix $\mathbf{O}$ is the same as the one of the $\mathbf{A}$ matrix, then the system is observable, i.e. the ability of the dynamic system to determine the state by working on the measured output $\mathbf{y}$.

This analysis is important for the control design algorithms. 


\section{STATE-FEEDBACK CONTROL}

For the system (8), whose schematic representation can be seen in Fig. 1, the state-feedback control law has the following general form:

$$
u=-\mathbf{K} x+\mathbf{P} r
$$

where $r$ is the set-point of the closed-loop system, $\mathbf{K}$ is the state-feedback matrix, and $\mathbf{P}$ is the pre-compensation matrix.

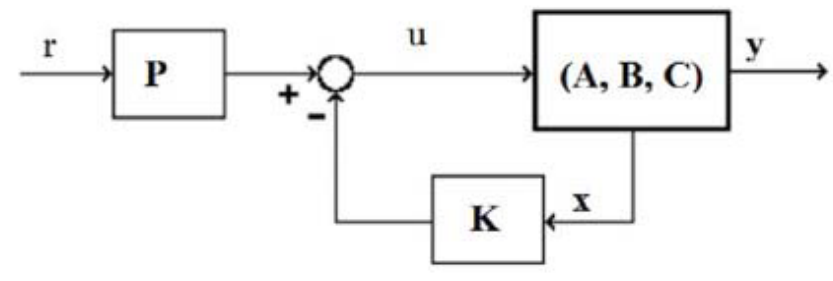

Fig. 1. State-feedback closed-loop system

The state-feedback closed-loop system from Fig. 1 has the following model:

$$
\left\{\begin{array}{l}
\left(\begin{array}{c}
\dot{p}_{i} \\
p_{x} \\
\dot{P}_{c}
\end{array}\right)=(\mathbf{A}-\mathbf{B K})\left(\begin{array}{c}
p_{i} \\
p_{c} \\
P_{c}
\end{array}\right)+\mathbf{B P}\left(\begin{array}{c}
A_{r} \\
x_{v}
\end{array}\right) \\
\left(\begin{array}{c}
W_{c i} \\
p_{i}
\end{array}\right)=\mathbf{C}\left(\begin{array}{c}
p_{i} \\
p_{x} \\
P_{c}
\end{array}\right)
\end{array}\right.
$$

With the notions presented in the section III, we can test the stability, controllability and observability properties of the system.

The state-feedback control can be improved with a LQR control law where the $\mathbf{Q}$ matrix can be obtained by means of genetic algorithms.

\section{Genetically enhanced optimal CONTRol}

\section{A. LQR Control}

$\mathrm{LQR}$ control consists in finding the command matrix $\mathbf{K}_{\mathbf{L Q R}}$ so that the command:

$$
u=-\mathbf{K}_{L Q R} x
$$

can minimize the integral performance index:

$$
J=\int_{t=0}^{\infty}\left(x^{\top} \mathbf{Q} x+u^{\top} \mathbf{R} u+x^{\top} \mathbf{N} u\right) d t
$$

The control matrix $\mathbf{Q}$ whose form is:

$$
\mathbf{Q}=\left[\begin{array}{cccc}
q_{1} & 0 & \ldots & 0 \\
0 & q_{2} & \ldots & 0 \\
\vdots & \vdots & \ddots & \vdots \\
0 & 0 & \ldots & q_{n}
\end{array}\right]
$$

is ought to be found by means of genetic algorithms.

\section{B. Genetic algorithms}

Genetic algorithms were invented by John Holland in the $60 \mathrm{~s}$ and represent an optimization technique inspired by nature.

In [12] is presented the functioning principle of the genetic algorithms: given an initial population of individuals (chromosomes) - which represent possible solutions of the optimization problem, they are set to compete one with another for survival. After each individual's evaluation (through the objective function or the fitness associated to each individual), the strongest are allocated with a greater chance of participating in the reproduction process than the weakest, the latter might as well not contribute at all in the reproduction process.

The first step of the reproduction process is represented by crossover and mutation. Next, the newly obtained children will compete with each other and, possibly, with their parents. Therefore, selecting the best parents and eliminating the weakest, the solution of the problem converges to the optimal solution.

In order to obtain the optimal solution by means of genetic algorithms, two directions of research are proposed: in the first case, the matrix defined in (16) to have the same element on the main diagonal and, in the second case, the main diagonal of the matrix having different elements.

\section{Simulation RESUlTS}

\section{A. Invariant model}

For the simulation of the invariant model with 4 inputs and 2 outputs from (6), we consider the following numerical values for the matrices $\mathbf{A}, \mathbf{B}$ and $\mathbf{C}$ :

$$
\begin{gathered}
\mathbf{A}=\left[\begin{array}{ccc}
-3.625 & 0 & 373.0841 \\
35.3698 & -93.4776 & 0 \\
0 & 0.0260 & -9.0909
\end{array}\right] \\
\mathbf{B}=10^{5} *\left[\begin{array}{cccc}
0.5714 & 0 & -0.000003 & 0 \\
-5.5755 & 0.1020 & 0.00003 & 1.4608 \\
0 & -0.0002 & 0 & 0
\end{array}\right] \\
\mathbf{C}=\left[\begin{array}{ccc}
0 & 0 & 0.0249 \\
1 & 0 & 0
\end{array}\right]
\end{gathered}
$$

According to (10), the corresponding controllability matrix is:

$$
\mathbf{C}_{\mathbf{o}}{ }^{T}=\left[\begin{array}{ccc}
57140 & -557550 & 0 \\
0 & 10200 & -20 \\
-0.3 & 3 & 0 \\
0 & 146080 & 0 \\
-207132 & 54139466 & -14496.3 \\
-7461.682 & -953471.5 & 447.018 \\
1.0875 & -291.04374 & 0.078 \\
0 & -13655207 & 3798.08 \\
-4657483 & -5068153605 & 1539410 \\
193823.9 & 88864311 & -28854.05 \\
25.1583723 & 27244.53 & -8.27 \\
1417003 & 1276456053 & -389563
\end{array}\right]
$$


The rank of the controllability matrix (18) is 3 , equal to the rank of the matrix $\mathbf{A}$ from (17), therefore the invariant system is controllable.

According to (11), the corresponding observability matrix is:

$$
\mathbf{O}=\left[\begin{array}{ccc}
0 & 0 & 0.0249 \\
1 & 0 & 0 \\
0 & 0.0006474 & -0.226 \\
-3.625 & 0 & 373.0841 \\
0.0229 & -0.0664 & 2.058 \\
13.14 & 9.7 & -4744.1
\end{array}\right]
$$

The rank of the observability matrix (19) is 3 , equal to the rank of the matrix $\mathbf{A}$ from (17), therefore the invariant system is observable.

The dynamic of the invariant model (6) can be observed in Fig. 2.

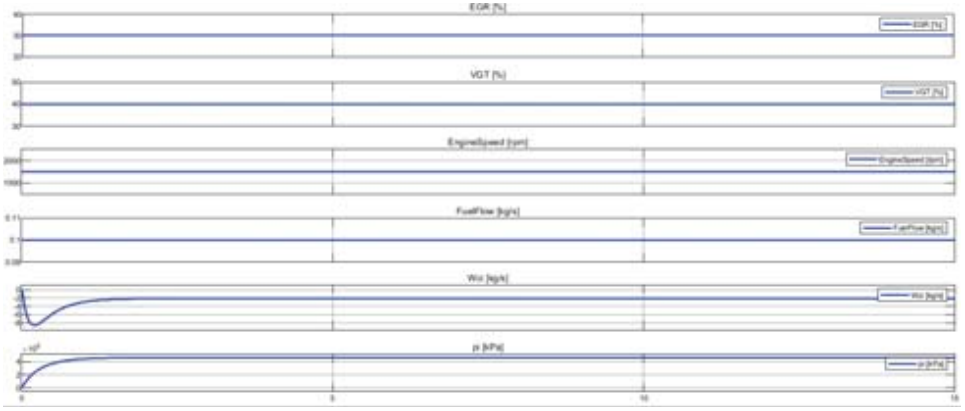

Fig. 2. Invariant model's dynamics

\section{B. Reduced invariant model}

For the simulation of the invariant model reduced to 2 inputs and 2 outputs from (7), we consider the following numerical values for the matrices $\mathbf{A}, \mathbf{B}$ and $\mathbf{C}$ :

$$
\begin{gathered}
\mathbf{A}_{\mathbf{r}}=\left[\begin{array}{ccc}
-3.625 & 0 & 373.0841 \\
35.3698 & -93.4776 & 0 \\
0 & 0.0260 & -9.0909
\end{array}\right] \\
\mathbf{B}_{\mathbf{r}}=\left[\begin{array}{cc}
57140 & 0 \\
-557550 & 10200 \\
0 & -20
\end{array}\right] \\
\mathbf{C}_{\mathbf{r}}=\left[\begin{array}{ccc}
0 & 0 & 0.0249 \\
1 & 0 & 0
\end{array}\right]
\end{gathered}
$$
is:

According to (10), the corresponding controllability matrix

$$
\mathbf{C}_{\text {or }}{ }^{T}=\left[\begin{array}{ccc}
57140 & -557550 & 0 \\
0 & 10200 & -20 \\
-207133 & 54139466 & -14496.3 \\
-7461.682 & -953472 & 447 \\
-4657484 & -5068153606 & 1539411 \\
193824 & 88864311 & -28854
\end{array}\right]
$$

The rank of the controllability matrix (21) is 3 , equal to the rank of the matrix $\mathbf{A}_{\mathbf{r}}$ from (20), therefore the invariant system is controllable.
According to (11), the corresponding observability matrix is:

$$
\mathbf{O}_{\mathbf{r}}=\left[\begin{array}{ccc}
0 & 0 & 0.0249 \\
1 & 0 & 0 \\
0 & 0.00065 & -0.2264 \\
-3.625 & 0 & 373.08 \\
0.0229 & -0.0664 & 2.05785 \\
13.141 & 9.7 & -4744.1
\end{array}\right]
$$

The rank of the observability matrix (22) is 3 , equal to the rank of the matrix $\mathbf{A}_{\mathbf{r}}$ from (20), therefore the invariant system is observable.

The dynamic of the reduced invariant model (7) can be observed in Fig. 3.

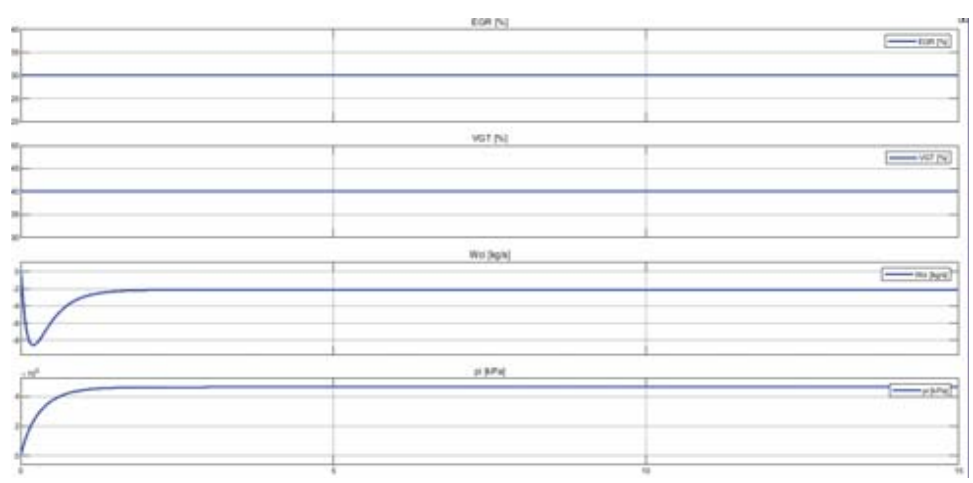

Fig. 3. Reduced invariant model's dynamics

We can observe from Fig. 2 and Fig. 3 that the dynamics of the reduced invariant model is similar to the one of the invariant model.

\section{State-feedback step response}

The state-feedback matrix $\mathbf{K}$ from (12) has the following numerical form:

$\mathbf{K}=\left[\begin{array}{ccc}-5.119 * 10^{-5} & -1.419 * 10^{-15} & 0.00653 \\ 7.905 * 10^{-18} & -0.0013 & 0.4295 \\ 2.92 * 10^{-10} & -2.7045 * 10^{-10} & -3.6805 * 10^{-8} \\ 4.67468 * 10^{-5} & -0.00054 & -0.00507\end{array}\right]$

The state-feedback control step response of (6) can be observed in Fig. 4.

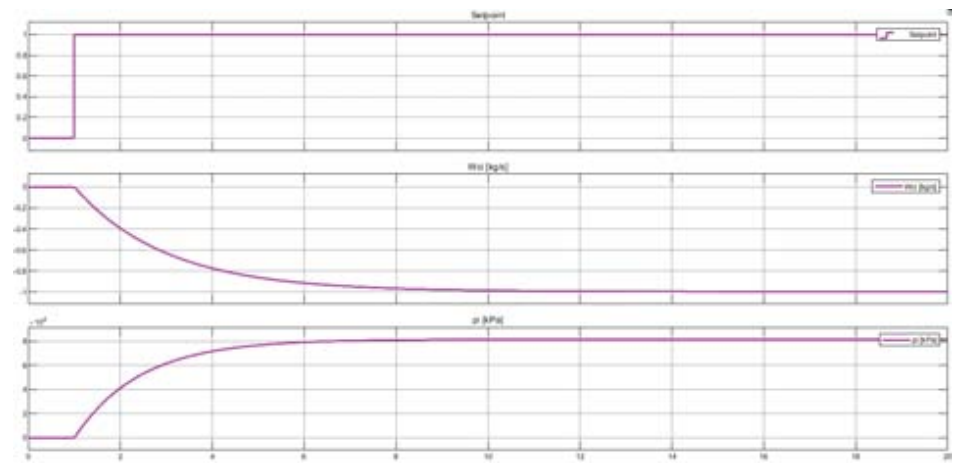

Fig. 4. State-feedback control step response of the invariant model

The state-feedback control step response of (8) can be observed in Fig. 5. 


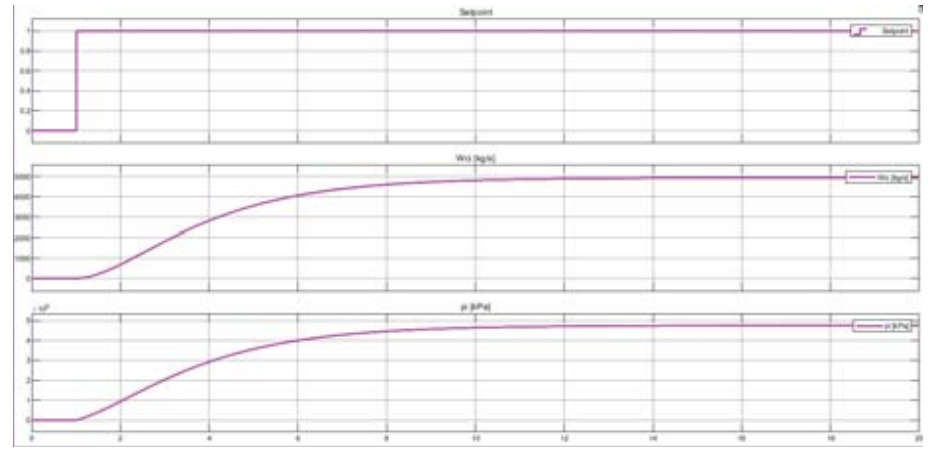

Fig. 5. State-feedback control step response of the reduced model

\section{Optimal control}

The matrices $\mathbf{Q}$ and $\mathbf{R}$ from (15) have the following form:

$$
\begin{gathered}
\mathbf{Q}=\left[\begin{array}{ccc}
0.0001 & 0 & 0 \\
0 & 0.01 & 0 \\
0 & 0 & 10
\end{array}\right] \\
\mathbf{R}=\left[\begin{array}{cccc}
100 & 0 & 0 & 0 \\
0 & 100 & 0 & 0 \\
0 & 0 & 100 & 0 \\
0 & 0 & 0 & 100
\end{array}\right]
\end{gathered}
$$

The corresponding matrix of the LQR control, $\mathbf{K}_{\mathbf{L Q R}}$, from (14) is:

$$
\mathbf{K}_{\mathbf{L Q R}}=10^{-5} *\left[\begin{array}{ccc}
25.61 & -948.68 & -836.25 \\
4.058 & 17.74 & -9834 \\
-8.72 * 10^{-5} & 5.11 * 10^{-3} & 5.45 * 10^{-3} \\
94.88 & 258.28 & 2140.7
\end{array}\right]
$$

The LQR control step response of (6) can be observed in Fig. 6.

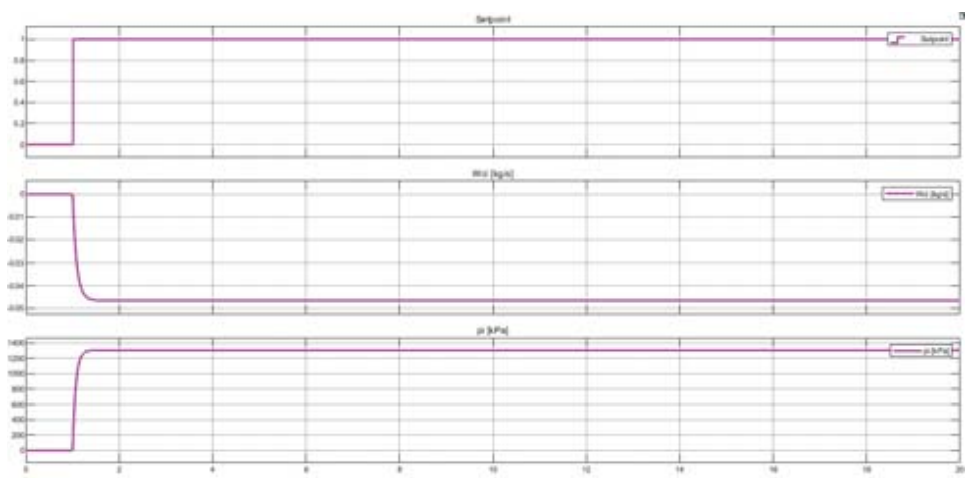

Fig. 6. LQR control step response of the invariant model

The LQR control step response of (8) can be observed in Fig. 7.

From Fig. 4 and Fig. 6 we can observe that the LQR control offers superior performances. The same observation applies for the reduced invariant model (Fig. 5 versus Fig. 7).

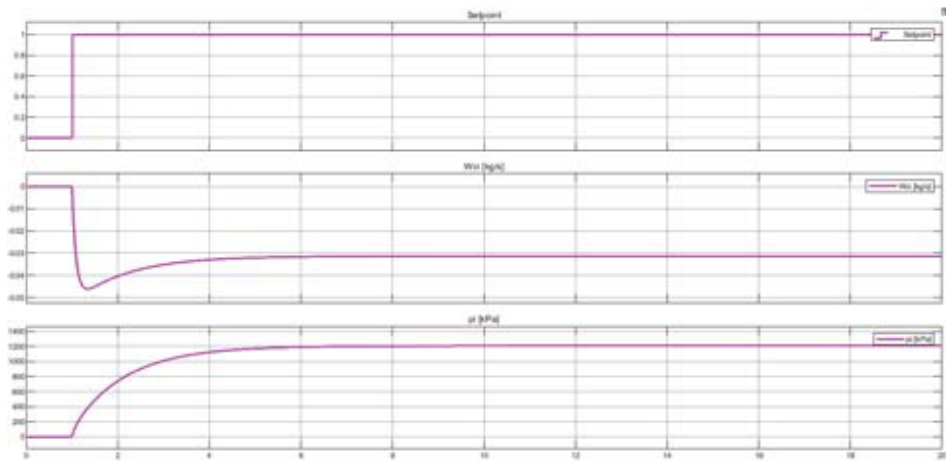

Fig. 7. LQR control step response of the reduced model

\section{CONCLUSIONS AND PERSPECTIVES}

The paper presents the dynamic models associated to the combustion regime of an experimental Diesel engine. Stability, controllability and observability analyses of the corresponding engine models have been performed. State-feedback control and LQR control procedures have been presented in order to control the air flow inside the intake manifold to the cylinders and the pressure inside the combustion chamber of an experimental Diesel engine platform.

The LQR control of the Diesel engine combustion regime can be improved by tuning its quadratic matrices by means of genetic algorithms. Also, the LQR control can be improved with a multi-model control in the following research studies.

\section{REFERENCES}

[1] C. P. Cho et al., "NOx reduction and $\mathrm{N} 2 \mathrm{O}$ emissions in a diesel engine exhaust using Fe-zeolite and vanadium based SCR catalysts", Elsevier, Applied Thermal Engineering 110, 2017, pp. 18-24.

[2] S. J. Schmiega et al., "Thermal durability of Cu-CHA NH3-SCR catalysts for diesel NOx reduction“, Elsevier, Catalysis Today 184, 2012, pp. 252261.

[3] Di Wang et al., "A comparison of hydrothermal aging effects on NH3SCR of NOx over Cu-SSZ-13 and Cu-SAPO-34 catalysts", Elsevier, Applied Catalysis B: Environmental, 2014.

[4] J. H. Kwak et al., "Effects of hydrothermal aging on NH3-SCR reaction over Cu/zeolites", Elsevier, Journal of Catalysis, 2012.

[5] M. F. Hsieh and J. Wang, "Nonlinear Observer Designs for Diesel Engine Selective Catalytic Reduction (SCR) Ammonia Coverage Ratio Estimation“, IEEE, 978-1-4244-3872-3, 2009.

[6] V. Thanigaivelan and Dr. M. Loganathan, "Performance analysis of addition of hydrogen to compression ignition diesel engine with bio diesel blends“, IEEE, 978-1-5090-4855-7, 2017.

[7] L. Thibault et al., "Reduction of pollutant emissions of diesel mild hybrid vehicles with an innovative Energy Management Strategy“, IEEE, 978-1-5090-4804-5, 2017.

[8] A.G. Sarah and B. S. Rajanikanth, "NOx Reduction from Biodiesel Exhaust by Plasma Induced Ozone Injection Supported by Lignite Waste Adsorption", IEEE Transactions on Dielectrics and Electrical Insulation Vol. 23, No. 4, 2016.

[9] S. Samokhin and K. Zenger, "High-pressure recirculated exhaust gas fraction estimation and control in marine diesel engines“, IEEE, 978-14799-7886-1, 2016.

[10] R. Stefan, C. Oara, "Teoria Sistemelor Automate - Note de curs", Bucuresti, 2013.

[11] S. Cirstoiu, D. Popescu, O. Pages, "MultiModel Adaptive Control for Turbocharged Diesel Engines", Proceedings of the 1st ICSCS International Conference, Villeneuve dAscq, France, IEEE, 2012.

[12] M. Mitchell, "An Introduction to Genetic Algorithms“, MIT Press, 1998.

[13] S. Cirstoiu and D. Popescu, "Multi-model adaptive control for turbocharged Diesel engines“, UPB Scientific Bulletin 2013, Seria C, vol. 75, nr.1, ISSN 1454-234x, pp. 59-68. 
[14] M. Jung, R. Ford , K.Glover, N. Collings, U. Christen, M. Watts, "Parameterization and Transient Validation of a Variable Geometry Turbocharger for Mean-Value Modeling at Low and Medium Speed Load points“, Society of Automotive engineers, Paper 2002-01-2729, 2002.

[15] L. Guzzella and A. Amstutz, "Control of Diesel Engines“, IEEE Control Systems Magazine, vol. 18, no.5, pp. 53-71, 1998.

[16] B.D.O. Anderson and J.B. Moore, "Optimal Control: Linear Quadratic Methods“, Englewood Cliffs, NJ: Prentice-Hall, 1990.

[17] J.W. Grizzle, J.A. Cook and W.P. Milam, "Improved air charge estimation for transient air fuel ratio control", Proc. of American Control Conference, Baltimore, MD, Paper TM01-1:30, 1994.

[18] M. Jung and K. Glover, "Calibratable linear parameter-varying control of turbocharged diesel engines", IEEE Transactions on Control Systems Technology, 14:45-62, 2006.

[19] C. Dimon, D.T. Genevieve, D. Popescu, I.A. Tache, "Numerical Control for Hydrodynamic Traffic Flow Models", 1st International Conference on Systems and Computer Science (ICSCS 2012), France, 2012. 